\title{
PRELIMINARY STUDY :FAKTOR DETERMINAN AKTIVITAS PARKIR KAPAL YANG BERPENGARUH TERHADAP KUALITAS AIR SUNGAI SILUGONGGO
}

\author{
Boby Rahman a, Muhammad Sidiq Aryanto ${ }^{b}$ \\ a,b Program Studi Perencanaan Wilayah dan Kota Universitas Islam Sultan Agung Semarang \\ email : bobyrahman@unissula.ac.id
}

Info Artikel:

- Artikel Masuk: 07/03/21

- Artikel diterima: 20/03/21

- Tersedia Online: 30/03/21

\begin{abstract}
ABSTRAK
Sungai Silugonggo merupakan salah satu sungai di Kabupaten Pati Kecamatan Juwana yang memiliki aktivitas sungai yang padat. Salah satu aktivitas Sungai Silugonggo adalah parkir kapal yang berjejer hingga muara laut. Aktivitas parkir kapal ini memiliki potensi untuk dapat mencemari sungai. Sehingga dianalisis variabel parkir kapal apa yang secara determinan dapat memberikan pengaruh terhadap pencemaran sungai. Dengan metodologi kuantitatif dan Teknik analisis determinan, maka didapatkan bahwa variabel lama waktu parkir kapal dan lama parkir berdasarkan ukuran kapal mempunyai pengaruh terhadap tingkat pencemaran sungai.
\end{abstract}

Kata Kunci : Parkir kapal, Analisis Determinan, Pencemaran Sungai

\section{ABSTRACT}

Silugonggo River is one of the rivers in Pati District, Juwana District, which has dense river activity. One of the activities of the Silugonggo River is parking the boats that line the mouth of the sea. This boat parking activity has the potential to pollute the river. So that the ship parking analysis variable can determinedly have an influence on river pollution. With quantitative methodology and determinant analysis techniques, it is found that the variables of ship parking time and length of time are determined based on the size of the ship which affects the level of river pollution.

Keywords: ship parking, determinant analysis, river pollution

\section{PENDAHULUAN}

Kawasan Pantai Utara Jawa atau sering disebut "Pantura" memiliki bentang luas pesisir yang Panjang, dan merupakan salah satu kawasan yang memiliki tingkat produktif yang baik (Saraswati, 2004). Faktor ini terbentuk karena kawasan pesisir pintura mempunyai jumlah muara sungai yang banyak sehingga memunculkan potensi seperti kandungan bahan organic yang cukup tinggi, selain itu produktivitas ini terbentuk karena tingginya keberagaman ekosistem pesisir seperti mangrove, pertambakan dan muara sungai yang dapat menjadi akses keluar masuk sungai dan laut (Zainuri, 2010). Keberagaman ekosistem pesisir pantai utara, memunculkan banyak kegiatan terutama ekonomi yang dapat berdampak terhadap kualitas lingkungan pesisir.

Salah satu sungai yang berada di kawasan pesisir pantai utara adalah Sungai Silugonggo. Sungai ini berada di Kecamatan
Juwana Kabupaten Pati Provinsi Jawa Tengah. Sungai Silugonggo menjadi sungai terbesar di Kecamatan Juwana, yang memiliki beragam aktivitas kegiatan seperti bersandarnya kapal, MCK, TPI, serta industry, sehingga memiliki potensi menimbulkan pencemaran pada kualitas air sungainya (Chauro Aina et al., 2017). Beberapa hasil pengujian kualitas air Sungai Silugonggo, menunjukkan hasil pencemaran yang melebihi bakumutu air (Arvianto et al., 2016; Chauro Aina et al., 2017; Hidayah et al., 2016). Hasil survey primer terkait tingkat ph pun juga berada di angka ph 8 dan 9 atau berada diatas baku mutu air.

Dari berbagai kegiatan terdapat aktivitas yang sangat dominan secara fisik di Sungai Silugonggo, aktivitas tersebut adalah parkir kapal. Aktivitas parkir kapal mempunyai potensi dalam pencemaran sungai salah satunya adalah pencemaran melalui tumpahan ataupun rembesan minyak yang berasal dari kapal (Darlan \& Kamiludin, 2016; Nedi, 2012; 
Ambariyanto, 2006). Selain itu lamanya parkir juga dapat membuat jatuhnya bekas-bekas barang bawaan kapal ke sungai yang dapat mencemari sungai secara warna dan bau. Dengan permasalahan diatas, maka dilakukan penelitian terkait factor determinan yang signifikan pada parkir kapal dalam mempengaruhi kualitas sungai Silugonggo.

\section{DATA DAN METODE}

Metodologi penelitian yang digunakan didalam penelitian ini adalah kuantitatif dengan teknik analisis diskriminan. Analisis diskriminan dilakukan untuk memperoleh sebuah persamaan yang dapat bermanfaat untuk memprediksi suatu objek masuk ke dalam salah satu kategori dari variabel tak bebas berdasarkan informasi dari objek tersebut. Pada analisis diskriminan, variabel bebas bersifat metrik (interval atau rasio) (Hair et al., 2010). Atau dengan kata lain Analisis diskriminan digunakan untuk memperkirakan hubungan antara dependen kategoris variabel dan satu set skala interval, Variabel independen.

Pada penelitian ini kategori variabel independennya adalah ukuran kapal yang parkir, jumlah kapal yang parkir, lama parkir kapal, dan lama parkir berdasarkan ukuran kapal. Sedangkan variabel dependen kategori adalah tidak terjadi pencemaran, cukup mencemari dan sangat mencemari. Dengan dua variabel tersebut maka dilakukan proses analisis diskriminan untuk mengetahui variabel independent mana yang secara signifikan mempengaruhi pencemaran sungai. Pencemaran sungai diteliti pada penelitian ini adalah pencemaran sungai melalui fisik (perubahan warna air sungai) dan bau.

Adapun komponen pertanyaan adalah sebagai berikut

Tabel 1. Variabel dan Indikator

\begin{tabular}{|l|l|}
\hline \multicolumn{1}{|c|}{ Variabel } & \multicolumn{1}{c|}{ Parameter } \\
\hline Berapa ukuran kapal & a. Kurang dari 80GT \\
\cline { 2 - 2 } perikanan yang parkir & b. 80-150GT \\
\cline { 2 - 2 } di Sungai Silugonggo & c. Lebih dari 150GT \\
\hline Berapa rata-rata & a. kurang dari 50 kapal \\
\cline { 2 - 2 } jumlah kapal yang & b. 50-100 kapal \\
\cline { 2 - 2 } $\begin{array}{l}\text { parkir dalam kurun } \\
\text { waktu satu minggu di } \\
\text { sungai silugonggo }\end{array}$ & c. Lebih dari 100 kapal \\
\hline
\end{tabular}

\begin{tabular}{|l|l|}
\hline \multicolumn{1}{|c|}{ Variabel } & \multicolumn{1}{c|}{ Parameter } \\
\hline Berapa lama durasi & a. Kurang dari 5 hari \\
\cline { 2 - 2 } $\begin{array}{l}\text { parkir kapal di sungai } \\
\text { silugonggo }\end{array}$ & b. 5-8 hari \\
\cline { 2 - 2 } $\begin{array}{l}\text { Berapa ukuran kapal } \\
\text { yang memiliki durasi } \\
\text { parkir terlama }\end{array}$ & a. Kurang dari 8 hari \\
\cline { 2 - 2 } & b. 80-150GT \\
\cline { 2 - 2 } & C. Lebih dari 150GT \\
\hline
\end{tabular}

Dengan jumlah populasi mencapai pada lokasi penelitian adalah 2.701 dan menggunakan taraf kesalahan $10 \%$ maka jumlah sampel adalah 466 sampel. Sasaran responden penelitian ini dilakukan pada nelayan pelaku parkir kapal serta para nelayan kecil pengguna Sungai Silugonggo Kecamatan juwana.

\section{HASIL DAN PEMBAHASAN}

\subsection{Kondisi Lokasi Penelitian}

Lokasi Studi berada di hilir Sungai Silugonggo yang terletak di Kecamatan Juwana, yang dimulai dari jembatan juwana hingga pulau Serapat dengan jarak sepanjang 2,2km. Hilir Sungai Silugonggo memiliki lebar serta kedalaman yang bervariatif yaitu memiliki lebar antara 60-100meter serta memiliki kedalaman antara 8-15 meter.

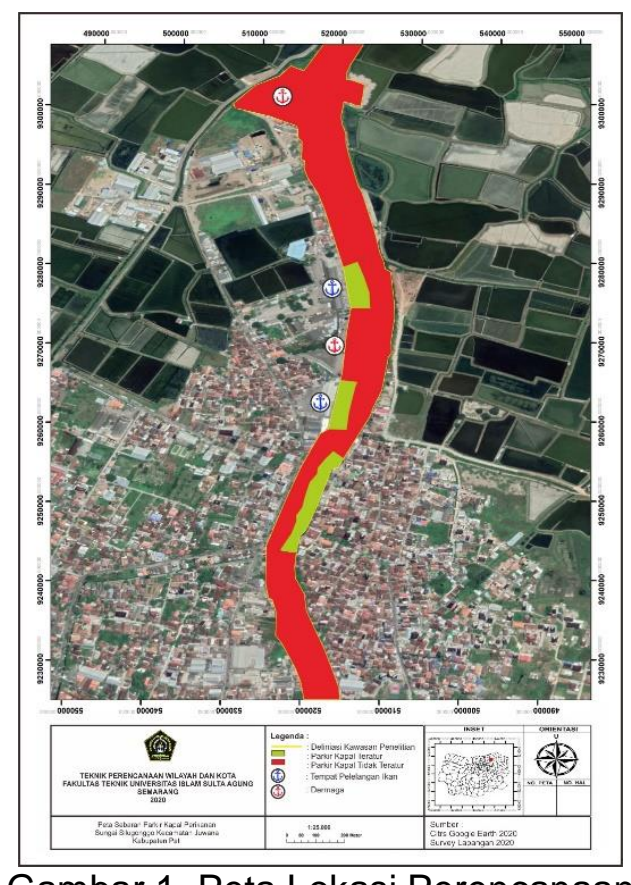

Gambar 1. Peta Lokasi Perencanaan 
Letaknya yang berbatasan langsung dengan laut jawa membuat sungai silugonggo menjadi pusat aktivitas perikanan untuk wilayah kecamatan juwana dan sekitarnya, hal tersebut menimbulkan beberapa dampak negatif bagi sungai maupun masyarakat sekitar sungai, banyaknya kapal perikanan besar yang parkir tidak teratur menyebabkan nelayan kecil tidak bisa melaut karena akses menuju ke laut terhambat oleh parkir kapal perikanan, selain itu banyaknya kapal yang parkir menyebabkan aliran sungai menuju ke laut menjadi terhambat sehingga menyebabkan sedimentasi pada sungai, hal ini diperparah dengan banyaknya bangkai kapal terbakar yang memperburuk sedimentasi sungai dan membuat sungai tercemar.

Jenis dan ukuran kapal perikanan di Sungai Silugonggo beragam, berkisar antara 30GT hingga lebih dari 100GT, semakin besar ukuran kapal maka memperlukan tempat yang luas untuk bersandar. Jika dilihat dari data kantor Unit Pelayanan pelabuhan kelas II juwana, terdapat berbagai jenis dan ukuran kapal perikanan yang parkir di sepanjang Hilir Sungai Silugonggo, diantaranya :

Tabel 1. Jumlah Kapal Parkir di Sungai Silugonggo

\begin{tabular}{|c|l|l|r|}
\hline No. & \multicolumn{1}{|c|}{$\begin{array}{c}\text { Jenis } \\
\text { Kapal }\end{array}$} & \multicolumn{1}{|c|}{ Ukuran } & \multicolumn{1}{|c|}{$\begin{array}{c}\text { Jumlah } \\
\text { Kapal }\end{array}$} \\
\hline 1. & $\begin{array}{l}\text { Kapal Purse } \\
\text { seine }\end{array}$ & $\begin{array}{l}\text { Lebih dari } \\
100 \mathrm{GT}\end{array}$ & 130 \\
\hline 2. & $\begin{array}{l}\text { Kapal pole } \\
\text { and line }\end{array}$ & $80-100 \mathrm{GT}$ & 70 \\
\hline
\end{tabular}

\begin{tabular}{|c|l|c|c|}
\hline No. & $\begin{array}{c}\text { Jenis } \\
\text { Kapal }\end{array}$ & Ukuran & $\begin{array}{c}\text { Jumlah } \\
\text { Kapal }\end{array}$ \\
\hline 3. & $\begin{array}{l}\text { Kapal } \\
\text { Longline }\end{array}$ & 30-80GT & 18 \\
\hline \multicolumn{2}{|c|}{ Jumlah } & 218 \\
\hline
\end{tabular}

Sumber : kantor Unit Pelayanan pelabuhan kelas II juwana

Jumlah kapal yang parkir di Sungai Silugonggo paling banyak yaitu kapal purse seine yang memiliki Ukuran lebih dari 100GT dengan jumlah 120 kapal, yang kedua adalah kapal perikanan pole and line dengan ukuran 80100GT dengan jumlah 70 kapal dan yang terakhir kapal perikanan longline dengan ukuran 30-80GT dengan jumlah 18 kapal.

Jumlah kapal perikanan terbanyak adalah kapal perikanan dengan jenis kapal purse seine yang memiliki ukuran lebih dari 100GT, semakin besar kapal maka semakin membutuhkan ruang sungai yang luas untuk parkir serta membutuhkan waktu yang lama untuk melakukan aktifitas bongkar muat hasil tangkapan ikan.

\subsection{Analisis Determinan}

Analisis determinan menghasilkan beberapa analisis perhitungan mulai dari group statistic, Tests of Equality of Group Means dan Variables Enter/Removed

Tabel 2. Group Statistic

\begin{tabular}{|c|c|c|c|c|c|}
\hline \multirow{2}{*}{\multicolumn{2}{|c|}{ Pencemaran }} & \multirow[b]{2}{*}{ Mean } & \multirow[b]{2}{*}{ Std. Deviation } & \multicolumn{2}{|c|}{ Valid N (listwise) } \\
\hline & & & & Unweighted & Weighted \\
\hline \multirow{4}{*}{ Tidak Mencemari } & Ukuran_Kapal & 2.2750 & .75064 & 40 & 40.000 \\
\hline & Jumlah_Kapal & 2.9500 & .31623 & 40 & 40.000 \\
\hline & Lama Parkir & 2.3000 & .46410 & 40 & 40.000 \\
\hline & $\begin{array}{l}\text { Lama_Parkir_Menurut_ } \\
\text { Ukuran }\end{array}$ & 2.3750 & .92508 & 40 & 40.000 \\
\hline \multirow[t]{4}{*}{ Cukup Mencemari } & Ukuran_Kapal & 2.3167 & .77002 & 60 & 60.000 \\
\hline & Jumlah_Kapal & 2.5333 & .50310 & 60 & 60.000 \\
\hline & Lama_Parkir & 2.4333 & .64746 & 60 & 60.000 \\
\hline & $\begin{array}{l}\text { Lama_Parkir_Menurut_ } \\
\text { Ukuran }\end{array}$ & 2.6167 & .49030 & 60 & 60.000 \\
\hline \multirow[t]{3}{*}{ Sangat Mencemari } & Ukuran_Kapal & 2.6639 & .59602 & 366 & 366.000 \\
\hline & Jumlah_Kapal & 2.6721 & .63818 & 366 & 366.000 \\
\hline & Lama_Parkir & 2.8579 & .46995 & 366 & 366.000 \\
\hline
\end{tabular}




\begin{tabular}{|c|c|c|c|c|c|}
\hline \multirow{3}{*}{ Pencemaran } & & \multirow[b]{2}{*}{ Mean } & \multirow[b]{2}{*}{ Std. Deviation } & \multicolumn{2}{|c|}{ Valid N (listwise) } \\
\hline & & & & Unweighted & Weighted \\
\hline & $\begin{array}{l}\text { Lama_Parkir_Menurut_ } \\
\text { Ukuran }\end{array}$ & 2.8552 & .40990 & 366 & 366.000 \\
\hline \multirow[t]{4}{*}{ Total } & Ukuran_Kapal & 2.5858 & 65100 & 466 & 466.000 \\
\hline & Jumlah_Kapal & 2.6781 & 60769 & 466 & 466.000 \\
\hline & Lama_Parkir & 2.7554 & .53302 & 466 & 466.000 \\
\hline & $\begin{array}{l}\text { Lama_Parkir_Menurut_ } \\
\text { Ukuran }\end{array}$ & 2.7833 & .50611 & 466 & 466.000 \\
\hline
\end{tabular}

Sumber : Hasil Olah SPSS, 2021

Dari hasil analisis group analisis, maka dapat diketahui bahwa lama parkir mempunyai nilai rata-rata statistik terbesar dalam kategori sangat mencemari dengan nilai 2,8579 berbeda tipis dengan lama parkir kapal menurut ukuran 2,8579 . Namun kedua angka tersebut secara statistik cukup berbeda jauh dengan dua variabel lainnya yaitu ukuran kapal yang parkir dan jumlah kapal. Hal ini menunjukkan bahwa ada perbedaan cukup jauh, namun masih harus diuji melalui tahapan tabel diskriminan berikutnya agar dapat mengetahuinilai signifikansinya.

Uji berikutnya adalah uji Tests of Equality of Group Means, uji ini bertujuan untuk apakah perbedaan rata-rata dari ketiga ketogori, yakni kategori tidak mencemari, cukup mencemari dan sangta mencemari berdasarkan masingmasing variabel bebas berbeda secara signifikan atau tidak.
Tabel 2. Tests of Equality of Group Means

\begin{tabular}{lc|c|r|r|r} 
& $\begin{array}{c}\text { Wilks' } \\
\text { Lambd }\end{array}$ & & df & & Sig \\
& a & F & 1 & df2 & \multicolumn{1}{c}{.} \\
\hline Ukuran_Kapal & .947 & 12.95 & 2 & 46 & .00 \\
& & 6 & & 3 & 0 \\
\hline Jumlah_Kapal & .975 & 5.843 & 2 & 46 & .00 \\
& & & & 3 & 3 \\
\hline Lama_Parkir & .861 & 37.38 & 2 & 46 & .00 \\
& & 0 & & 3 & 0 \\
\hline $\begin{array}{l}\text { Lama } \\
\text { Parkir_Menurut_Uku } \\
\text { ran }\end{array}$ & .914 & 21.74 & 2 & 46 & .00 \\
\hline
\end{tabular}

Sumber : Hasil Olah SPSS, 2021

Nilai sig untuk ukuran kapal, lama parkir dan lama parkir kapal menurut ukuran menunjukan angka sig 0.00 atau masih kurang dari 0.005 yang artinya nilai rata-rata memberikan pengaruh yang signifikan. Sedangkan jumlah kapal yang parkir mempunyai nilai sig 0.003 atau masih kurang dari 0.005 artinya nilai rata-ratanya juga memberikan pengaruh yang signifikan.

Tabel 3. Variables Entered/Removed

\begin{tabular}{|c|c|c|c|c|c|c|c|}
\hline \multirow[b]{3}{*}{ Step } & \multirow[b]{3}{*}{ Entered } & \multicolumn{6}{|c|}{ Min. D Squared } \\
\hline & & \multirow[b]{2}{*}{ Statistic } & \multirow[b]{2}{*}{ Between Groups } & \multicolumn{4}{|c|}{ Exact $\mathrm{F}$} \\
\hline & & & & Statistic & df1 & df2 & Sig. \\
\hline 1 & $\begin{array}{l}\text { Lama } \\
\text { Parkir_Menurut__ } \\
\text { Ukuran }\end{array}$ & .242 & $\begin{array}{l}\text { Cukup Mencemari and Sangat } \\
\text { Mencemari }\end{array}$ & 12.471 & 1 & 463.000 & .000 \\
\hline 2 & Lama_Parkir & .290 & $\begin{array}{l}\text { Tidak Mencemari and Cukup } \\
\text { Mencemari }\end{array}$ & 3.472 & 2 & 462.000 & .032 \\
\hline 3 & Jumlah_Kapal & .948 & $\begin{array}{l}\text { Cukup Mencemari and Sangat } \\
\text { Mencemari }\end{array}$ & 16.217 & 3 & 461.000 & 4.893E-10 \\
\hline 4 & Ukuran_Kapal & 1.094 & $\begin{array}{l}\text { Tidak Mencemari and Cukup } \\
\text { Mencemari }\end{array}$ & 6.523 & 4 & 460.000 & $4.112 \mathrm{E}-5$ \\
\hline
\end{tabular}

Sumber : Hasil Olah SPSS, 2021

Dari hasil tabel Variables Enter/Removed dapat diambil informasi bahwa variabel lama parkir menurut ukuran kapal dan variabel jumlah kapal yang parkir memberikan 18 
factor determinan terhadap pengaruh dalam cukup mencemari dan sangat mencemari Sungai Silugonggo. Hal ini dapat terbentuk karena kedua varibel lama parkir menurut ukuran kapal dan variabel jumlah kapal memiliki keterhubungan yaitu terkait dengan lamanya sebuah ukuran kapal yang parkir dengan jumlah ukuran kapal yang parkir.

\section{SIMPULAN}

Dari hasil analisis, maka dapat diketahui bahwa keempat variabel memiliki signifikasansi dalam memberikan pengaruhnya terhadap pencemaran Sungai Silugonggo. Namun untuk varibel yang memiliki signifikansi untuk memberikan pengaruh terhadap kategori cukup mencemari dan sangat mencemari adalah variabel lama parkir menurut ukuran kapal dan variabel jumlah kapal yang parkir. Hal ini menunjukkan bahwa semakin banyak ukuran kapal besar (semakin besar dari kurang 50 GT hingga 150 GT) maka akan berpotensi mencemari sungai secara cukup mencemari hingga sangat mencemari. Begitupula pada lama parkir, semakin lama parkir kapal (lebih dari 8 hari) maka akan akan berpotensi mencemari sungai secara cukup mencemari hingga sangat mencemari.

\section{REFERENSI}

Ambariyanto, A., Nugroho, D., \& K Radjasa, O. (2006). Pelatihan Panduan Penanganan Pencemaran Laut Kepada Masyarakat Sebagai Upaya Peningkatan Kelestarian Lingkungan. Universitas Diponegoro

Arvianto, S. E., Satriadi, A., \& Handoyo, G. (2016). Pengaruh arus terhadap sebaran sedimen tersuspensi di muara sungai silugonggo kabupaten pati. Jurnal oseanografl, 5(June), 116-125.

Chauro Aina, L., Rita S.D., E., \& Kaswinarni, F. (2017). Biomonitoring Pencemaran Sungai Silugonggo Kecamatan Juwana Berdasarkan Kandungan Logam Berat (Pb) Pada Ikan Lundu. BIOMA Jurnal IImiah Biologi, 5(2), 1-11. https://doi.org/10.26877/bioma.v5i2.1498

Darlan, Y., \& Kamiludin, U. (2016). Penelitian Lingkungan Pantai Dan Logam Berat
Perairan Pariaman - Padang-Bungus Teluk Kabung Sumatera Barat. Jurnal Geologi Kelautan, $6(1)$, 12-22. https://doi.org/10.32693/jgk.6.1.2008.146

Hair Jr, Joseph, F., Black, W. C., Babin, B. J., \& Anderson, R. E. (2010). Multivariate Data Analysis (Vol. 7). Prentice-Hall.

Hidayah, G., Wulandari, S. Y., \& Zainuri, M. (2016). Studi Sebaran Klorofil-a Secara Horizontal di Perairan Muara Sungai Silugonggo Kecamatan Batangan, Pati. Buletin Oseanografi Marina, 5(1), 52. https://doi.org/10.14710/buloma.v5i1.1129 6

Saraswati, A. A. (2004). Konsep Pengelolaan Ekosistem Pesisir (Studi Kasus Kecamatan Ulujami, Kabupaten Pemalang, Jawa Tenggah. Tek.Lingk, 5(3), 205-211.

Nedi, S. (2012). Stakesholder yang Berperan dalam Pengendalian Pencemaran Minyak di Selat Rupat. Jurnal Perikanan dan Kelautan, 17(01).

Zainuri, M. (2010). Kontribusi Sumberdaya Fitoplankton Terhadap Produktivitas dan Keseimbangan Ekosistem dalam Pengelolaan Wilayah Pesisir. Pengukuhan Guru Besar Universitas Diponegoro Semarang, 78. 